\title{
Studies on the Toxicology of the Palmyrah palm (Borassus flabellifer L): Part II. Milk Transfer of Toxicity to Suckling Rats
}

S. N. Arseculeratne, Department of Microbiology, University of Peradeniya, Peradeniya, Sri Lanka

A. A. L. Gunatilaka,

Department of Chemistry, University of Peradeniya, Peradeniya, Siri Lanka

AND

R. G. PANaBokke

Department of Pathology, University of Peradeniya, Peradeniya, Sir Lant:a

(Date of receipt : 02 December 1982)

(Date of accentance : 19 Jantary 1983)

\begin{abstract}
Flour from the young shoot of the Palmyrah palm is consumed by humans in some Asian and African countries ; their traditional pharmacopoiea includes palmyrah products as therapeutic agents. This flout has previously becn reported to pro. duce acute and chronic toxic effects in rats. We report here thet feeding of diets containing palmyrah flour to lactating rats resulted in hepatic, pulmonary and renal lesions with subcutaneous haemorhhages in the suckling iats. The lesions were mainly vascular with diffuse haemorrhages or severe sinusoida! congestion in the liver, haemorrhages in the pulmonary alveolar septa with non-expansion of the lung; and intertubular congestion in the kidneys. With 100\%,50\% and 33\% flour diets, lethality occurred in the neonates within one week, 10 days and two weeks respertively. The significance of these results on liver damage in human infants through maternal consumption of this flour is discussed.
\end{abstract}

\section{Introduction}

Flour from the young shoot of the palmyrah palm (Borassus flabellifer $L$ ) is consumed by humans in some tropical countries including Sri Lanka, both as a food and as a traditional medicine. This flour when fed to rats, was reported to produce hepatotoxic and neurotoxic effects with lethality after short term, high dose feeding ${ }^{1}$ central and portal veno-occlusive reactions with hepatic fibrosis ${ }^{5}$ and immunosuppressive effects ${ }^{2}$ on prolonged feeding.

Toxic compounds, including a few of plant origin, have been reported ${ }^{3,4,6}$ to be excreted through milk and it was therefore of interest to investigate a possible transfer of palmyrah toxicity through milk as a possible route of intoxication. of young animals which are also reported to be more susceptible to some hepatotoxic agents.

This report describes the investigation of the effects of the consumption of palmytah flour by lactating rats, on their suckling offspring; we report that intoxication resulting in hepatic, pulmonary and renal lesions with lethality were produced in the suckling neonates. 


\section{Experimental}

2.1 Flour. Flour was obtained by pulverising, recently processed (boiled and sundried) mould-free shoots which were in the form in which they are normally consumed by humans in this country. The flour was stored at $4^{\circ} \mathrm{C}$ to prevent microbial spoilage. Flour from 5 different batches of shoots was tested. No contamination with aflatoxin or commonly used agrochemicals (organophosphates, chlorinated hydrocarbons and paraquat) was detected in these batches.

Palmyrah flour has a calorie equivalent of $340.6 \mathrm{Kcal} / 100 \mathrm{~g}$, producing a calorie intake of $50 \mathrm{Kcal} / 150 \mathrm{~g}$ rat/day with a $100 \%$ flour dietary consumption of $15 \mathrm{~g}$ per day.

2.2 Rats and feeding. Pregnant Wistar rats were maintained in individual cages and fed on their normal diet of rat pellets (approximate consumption - $15 \mathrm{~g} / \mathrm{rat} /$ day) with water ad lib., till parturition. Immediately after parturition, the test diet (15 g/rat/day) of $100 \%, 50 \%$ or $33 \%$ palmyrah flour in pellet powder was introduced with water ad lib. The experiments were terminated well before weaning began and this together with the inaccessibility of the food to the young, excluded the possibility of direct ingestion of the test diet by the neonates. Normal infants of comparable age, from mothers fed. with similar amounts of pellet powder alone, were used as controls for histopathology.

Fourteen lactating rats and 86 infants were studied; histological studies were made on 44 of the infants.

2.3 Histology. Tissues from infant rats (either killed with di-ethyl ether or examined. soon after death from intoxication) were fixed in $10 \%$ formol-saline for paraffin embedding. Sections $5, \mu$ in thickness were stained with haematoxylin and eosin $(\mathrm{H} \& \mathrm{E})$ and reticulin stains.

The livers of intoxicated lactating rats which died during the course of the experiments or were killed after the death of all the infants, were also examined similarly for histological confirmation of palmyrah toxicity.

\section{Results}

3.1 General effects. The toxicity of the flour was confirmed by the development of the typical symptoms of palmyrah toxication in the mother rats-pilo-erection, excitability, spasms of the limbs and head, followed by inactivity, laboured respiration and death. and by histology of the liver which showed centrilobular sinusoidal congestion. These effects were most marked with $100 \%$ and $50 \%$ flour within $5-10$ days of feeding.

Intoxicated infants did not show the neurotoxic symptoms (excitability and spasms) even when the mother was on a $100 \%$ flour diet, but appeared less active had a shrivelled skin and retardation of growth. 
3.2 Lethality. With $100 \%$ flour in the maternal diet, neonatal deaths occurred within the first and seventh day. With 50\% and $33 \%$ diets, survival was prolonged to approximately 10 days and 2 weeks respectively. The survival period thus appeared to be dose dependent. None of the infants of the palmyrah fed mothers, at any of the 3 dose levels survived beyond the second week.

3.3 External abnormalities. In 8 infants which survived for more than 4 days with a maternal diet of $100 \%$ flour, subcutaneous haemorrhages appeared at the extremities of the tail and limbs, and in the thoracic and abdominal walls. Spontaneous amputation of the discoloured tail or limb extremities occurred in some of these infants.

3.4 Internal abnormalities. In fatal cases, the neonatal liver was darker than in normal infants of the same age; the discolouration was unevenly distributed among the liver lobes. Free pleural or peritoneal fluid was seen in 3 infants; the kidneys were enlarged and pale in 2. Neither intestinal haemorrhage nor oedema of the viscera, which were described by Schoental ${ }^{6}$ in pyrrolizidine alkaloidal intoxication, was seen in the palmyrah intoxicated infants.

These abnormalities were seen with $100 \%$ and $50 \%$ maternal palmyrah diets.

3.5 Histopathology. In general, the intensity of the histopathological abnormalities in the infants appeared to be proportional to the concentration of the flour in the maternal diet, rather than to the duration of survival.

The discoloured patches in the tail, thoracic and abdominal walls and in the limbs consisted of extensive subcutaneous haemorrhages although no clear evidence of vascular distuption to account for the haemorrhages, was detected. In the tail, the haemorrhage was accompanied by oedema of the subcutaneous tissues and necrosis of the cartilaginous cells.

3.6 Liver. The most marked and consistent neonatal histological abnormalities were seen in the liver. Mild to intense centrilobular sinusoidal congestion with gross dilation of the sinusoids and focal haemorrhages, with $100 \%$ and $50 \%$ flour, were the most obvious lesions (Figure 1). Except with 100\% flour when the vascular abnormalities were intense and diffuse throughout the liver lobes, lower doses of flour produced an irregular distribution of these lesions, some lobes appearing relatively unaffected. This correlated. with the macroscopic discoloration of the liver lobes in these infants. The focal nature of the haemorrhages contrasted with extensive centrilobular pools of extravasated blood which are reported to be seen in nitrosamine intoxicated adult rats.

Neither central venous disruption, veno-occlusive reactions whch are seen in adult rats fed on sub-lethal doses of palmyrah flour, nor thromboses of the veins, were seen in our infant rats. 


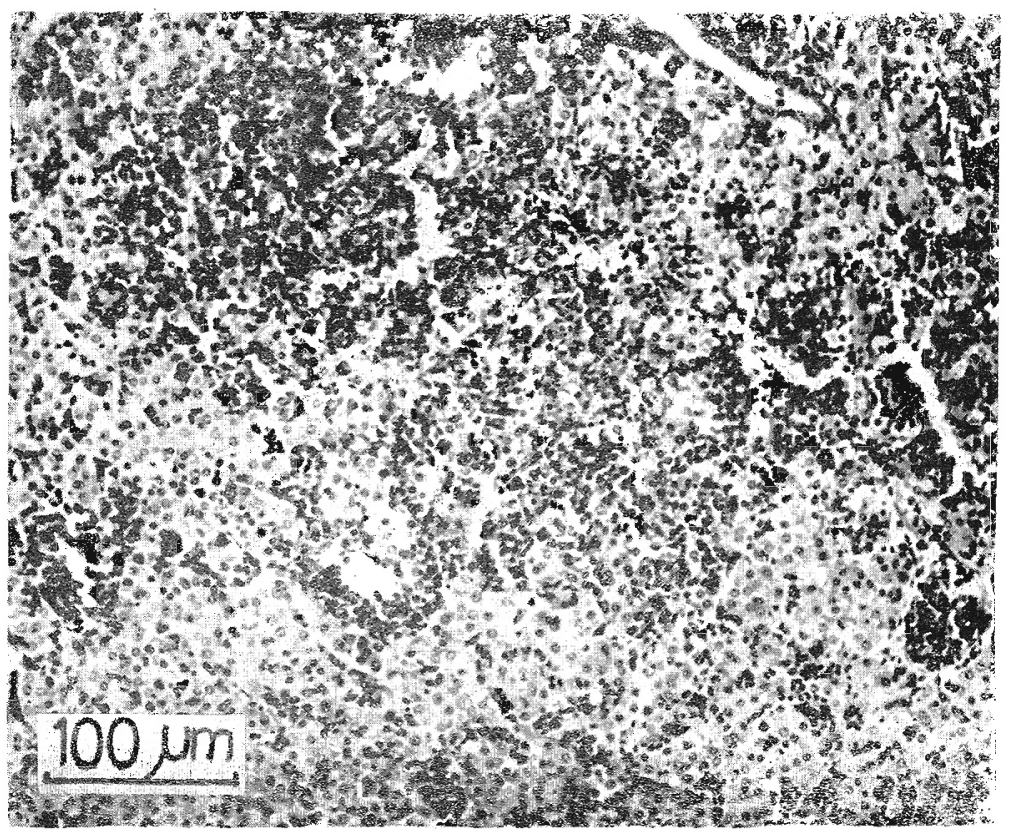

Figure 1. Diffuse vascular congestion and hamorrhage in the liver of a suckling rat, with a maternal diet of $100 \%$ paimyrah flour. H \& E. x 200.

The hepatocellular lesions consisted of cloudy swelling in mildly intoxicated infants, with hydropic degeneration in more severe cases with a maternal diet of $100 \%$ flour. Hepatocellular necrosis was remarkably absent as in adult intoxicated rats, contrasting with the necrotising effects of other hepatotoxic agents such as the nitrosamines, aflatoxins and carbon tetrachloride.

With extensive congestion and haemorrhages, extra-medullary erythropoetic foci in the liver were absent.

3.7 Lmings. Vascular congestion was the commonest lesion. With 100\% and 50\% flour, the congestion was severe, accompanied by scattered foci of haemorrhage into the alveolar septa; in 8 rats which showed these lesions, the apices of the lungs showed macroscope congestion or haemorrhage. Non-expansion of the alveoli which was present in 10 neonates appeared to correlate with the degree of vascular congestion and haemorrhage and could have resulted from a depression of respiration with intoxication.

In 8 infants the intensity of the congestion and haemorrhage into the liver was not paralleled by the degree of congestion in the lungs, suggesting that the liver lesions were a direct toxic effect on the vasculature rather than a passive effect from central venous congestion. 
3.8 Spleen. In only 1 infant did the spleen show vascular congestion. The absence of splenic congestion in infant rats which showed hepatic vascular' abnormalities, also supports the possibility that the hepatic lesions were a direct toxic effect of the palmyrah flour.

3.9 Kidney. Mild to moderate intertubular vascular congestion was the only rena1 lesion in 13 infants.

\section{Discussion}

Schoental ${ }^{6}$ investigated the effect on suckling rats of pyrrolizidine alkaloids (PA) administered. parenterally to lactating mother' rats and reported. that with the doses used, the liver lesions in the infants were most marked at 3 to 7 weeks of age. Noteworthy differences between her findings and ours included the occurrence of intestinal haemorrhages, fatty changes in the liver with bile duct proliferation and central venous lesions (thickening of the venous walls with narrowing of the lumen) in PA poisoning. We have described ${ }^{5}$ differences between the palmyrah induced lesions in adult rats and those of PA poisoning; these together with our findings described in this report further support our conclusion that palmyrah toxicity is not due to pyrrolizidine alkaloids.

A further difference between Schoental's PA lesions and the palmyrah induced lesions was that with the doses used, PA did not produce intoxication in the mother rat although lesions were well marked in the suckling infants. In our experiments. the lactating mothers too showed simultaneous clinical and histopathological evidence of palmyrah intoxication. The infant rats in our experiments showed macroscopic and microscopic evidence of intoxication within the first week of life contrasting with the delay of 2 to 3 weeks in the development of PA lesion observed by Schoental. Whether this difference is due to a dose related effect or to differences between PA and palmyrah toxin (s) in their modes of action, is at present obscure.

We have observed (Arseculeratne, unpublished data) that death with $100 \%$ flour occurred more rapidly with younger rats (1 to 2 months of age) than in adult rats; this might suggest that infant rats in the present experiments developed more intense lesions than their mothers on account of age dependent susceptibility, as has been described of other hefatotoxins, notably aftatoxin and the pyrrolizidine alkaloids.

The histological lesions too, in the liver and the lungs of our infant rats were more intense than the lesions in the corresponting mother rats. Whether this indicates a. greater susceptibility of the infants, the excretion through milk of a more toxic njetabolite, a concentration of the original palmyrat: toxin in rilk such as through binding to milk proteins or an activation of the original flour toxin during its passage through the mammary gland, remains to be elucidated. 
We have previcusly remarked the relatively insignificant hepatocellular abnormalities even in fatal cases of palmyrah intoxication in adult rats, the main lesions having been in the vasculature. In the intoxicated infant too, the hepatocellular lesions were not co-extensive with the vascular lesions. This contiasts with the effects of nitrosamines and aflatoxin.

Other plant sources, toxins from which have been shown to be transferred through milk include locoweeds ${ }^{4}$, Bracken fern ${ }^{3}$, and Cycas sp.

Our findings may also provide an alternative approach to the isolation and identification of the palmyrah toxins as excreted. through milk, and the investigation of a possible metabolic transformation of flour toxins into more toxic derivatives:

These findings also suggest that maternal consumption of palmyrah flour may result in toxic liver damage in infants which may contribute to the relatively high incidence of chronic liver disease in humans in Asian and African countries.

\section{Acknowledgements}

This work was supported by grants from the Natural Resources, Energy and Science Authority (Sri Lanka). We thank Mr. G. Gunasekara for technical assistance and Mr. K. D. Henry (Government Analyst's Department, Sri Lanka) for the analysis of agrochemicals.

\section{References}

1. Arseculeratne, S. N., Panabokke, R. G., Tennekoon, G. E. \& Bandunatha, C.H.S.R. (1971). Brit. J. exp. Path., 51 : 524.

2. Arseculeratne, S. N., Sirisinha, S., Charupatana, C: \& Kangwanpong, D. (1981). Proc. Soc. exp. Biol. Mec., 168: 356 .

3. Evans, I. A., Jones, R. A. \& Mainwaring-Burton, R. (1972). Nature, (Lond), 237: 107.

4. JAMES, L. F. \& Van KAMPEN, K. (1976). Amer. J. vet. Research, 37: 845.

5. Panabokke, R. G. \& Arseculeratne, S. N. (1976). Brit. J. exp. Path., 57 : 189.

6. Schoental, Regina (1959). J. Path. Bact., 77: 485. 